\title{
A Quantitative Method for the Creation of Typologies for Qualitatively Described Objects
}

\author{
Shannon Martino and Matthew Martino
}

In our natural attempts to determine patterns and similarity, certain attributes come to be considered more important than others. We attempt to find patterns even when they may not exist. This is well illustrated by the reaction to a famous question posed by Lewis Carroll's Mad Hatter in Alice's Adventures in Wonderland: "Why is a raven like a writing desk?" In the preface to the 1896 edition of the book Carroll says:

Enquiries have been so often addressed to me, as to whether any answer to the Hatter's riddle can be imagined, that I may as well put on record here what seems to be a fairly appropriate answer, viz: "Because it can produce few notes, tho [sic] they are very flat; and it is never put with the wrong end in front!" This, however, is merely an afterthought; the Riddle, as originally invented, had no answer at all.

While Carroll eventually gave into popular demand and provided an answer to this riddle, the continued fascination of his readers with this one particular phrase speaks to the human urge to find similarities between any two given objects. It is this urge, along with the oft-noted urge to detect differences, that makes classification such a natural part of the human character and one so prone to subjective conclusions.

Typologies are used by archaeologists to easily identify objects that are similar to each other by classifying similar artifacts into groups so that one can speak of a "type" rather than an individual object. And, initially, differences between these types were seen to be indications of cultural difference. This practice of classification, a key concept in Western scholarly thought, which is its own academic field, ${ }^{1}$ is the underpinning of much archaeological dating. ${ }^{2}$

1 Gordon 1999.

2 Roy and Reason 1979.

(C) SHANNON MARTINO AND MATTHEW MARTINO, 2018 | DOI 10.1163/9789004375086_006

This is an open access chapter distributed under the terms of the prevailing CC-BY-NC License. 
Yet subjectivity in typologies is unavoidable given the essentializing nature of typologies as well as their inherently sociopolitical nature. ${ }^{3}$ As Sorin Hermon and Franco Niccolucci have stated, "One of the major 'weaknesses' of typological research is the nature itself of types - being defined partly intuitively and partly rationally, [they are] partly essential and partly instrumental, most typological lists are polythetic, so there are no fixed criteria of 'typehood."'4 Historically, the types defined in archaeological typologies have been viewed as distinct entities that have meaning within the culture to which they belong, and, in the first half of the 190os, they were thought to be the most objective way to study ancient peoples. ${ }^{5}$ By the late 1960 , however, it was recognized that archaeological types are defined by the archaeologist in ways that may not reflect the types defined by the prehistoric peoples. ${ }^{6}$

Some, such as William and Ernest Adams, have entirely dismissed the necessity of complete objectivity in the creation of typologies and even the discussion of objectivity when it comes to typologies, saying "useful typologies require intersubjective agreement," i.e., a relationship between the work of all scholars on the subject. ${ }^{7}$ They further note that the "development of type concepts" is contingent on the collection of objects being studied. ${ }^{8}$ Moreover, they suggest that while initial types are often created through an intuitive recognition of similarity, later types are defined by difference from the very beginning of their recognition. ${ }^{9}$

When scholars look to create a typology, however, they try to distance themselves from assumptions of similarity and difference. Those assumptions are unavoidably colored by the invaluable knowledge of the times in which the object was created, as well as by previous research on the subject—but also by one's possibly flawed understanding of which particular aspects of the object indicate human agency, and which were necessitated by the functionality and material composition of the object. One must ask oneself not what a defining attribute of that object is, but what it could be, and then must be brutally honest about what one sees. If we are not careful, what might be viewed a significant factor to us but not to the producer of an object can be heavily influential

3 Gnecco and Langebaek 2014, v.

4 Hermon and Niccolucci 2002, 217.

5 Hermon and Niccolucci 2002, 218.

6 Tixier 1967.

7 Adams and Adams 1991, 4.

8 Adams and Adams, 1991, 53.

9 Adams and Adams, 1991, 54-55. 


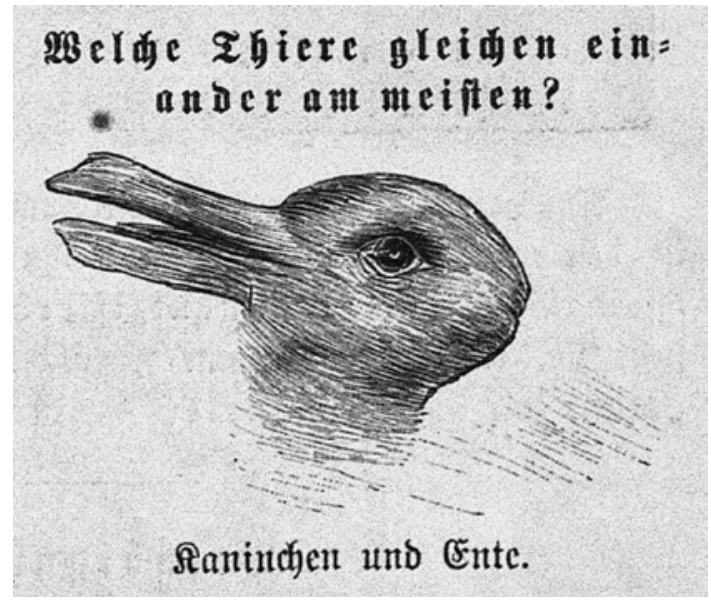

FIGURE 4.1

Fliegende Blätter, October 23, 1892

in the creation of a typology. In other words, the aspects of an object's production could be unnecessarily sidelined in favor of decoration, form, and presumed use. More than this, though, were typologies simply to be viewed as abstractions of data with no historical relevance to creation of the artifact itself, each independently created typology would be different. Thus each typology's utility in every case would have to be rigorously justified by the scientific question posed by the researcher. ${ }^{10}$

People's susceptibility to getting stuck seeing one thing when another is possible was satirized long ago by the rabbit/duck image, which seems to have first been published in Fliegende Blätter, a German humor magazine in Munich, ${ }^{11}$ and was picked up that same year by Harper's Weekly (Fig. 4.1). ${ }^{12}$

The original text asked, "Which animals are the most similar to each other?" The answer was "rabbit and duck." But studies by the Bruggers in the 199os found that what animal people see in the image can be influenced by the date on which they see the image. For example, children who see the image near Easter are more likely to see a rabbit. ${ }^{13}$

10 Thank you to Elena Rova for presenting this insight.

11 A facsimile of this image in Fliegende Blätter is available from the University of Heidelberg historical literature collection: <https://doi.org/10.11588/diglit.2137\#0147> (accessed May 20, 2017).

12 Brugger 1999.

13 Brugger and Brugger 1993. 
Though such extraneous happenings can affect what we see, the methodology for the creation of archaeological typologies is little discussed by their creators. ${ }^{14}$ In this sense, it is much like the creation of sausage, for as much as one would like to ignore how the sausages are made, the methodology behind one's typology should be as clear as the linkages that eventually arise from its completion. Without a clear system of analysis, all typologies are leaps of faith and intuition. Adams and Adams even point to intuition as the way in which initial types are often created from a collection of objects. ${ }^{15}$ While intuition often leads to discovery, a scientific argument builds "on such an intuition, shows how the linkage is possible, and therefore [is] arguable" rather than entirely subjective. ${ }^{16}$ Because the reasoning from points $\mathrm{A}$ to $\mathrm{Z}$ is clear, the whole is clear. By presenting the reader with the details of this methodology in two separate case studies, we hope to make our own typological creation as transparent as possible. Admittedly, as with many ideas, intuition led to the project's creation.

\section{Case Studies Background}

Using the method proposed here, the first case study presents the creation of a typology for a database of figurines, and the second case study creates a typology for a set of pottery. The first study compares Late Chalcolithic and Early Bronze Age (c. 5000-2500 BCE) clay anthropomorphic figurines from Bulgaria, Romania and Turkey by creating a FileMaker database of almost 2000 figurines. ${ }^{17}$ Such a large and seemingly disparate corpus was chosen for analysis in order to elucidate some of the contemporaneity of figurine production and decoration trends in the analyzed areas. Though many scholars have previously noted the stylistic similarity of these figurines, definitive chronological relationships eluded them. ${ }^{18}$ Those who noted the contemporaneity of figurines from the areas of Bulgaria, Romania, and Turkey tended to focus on earlier periods such as the Neolithic. In that period, presumably the figurines of both Greece and Turkey were similar not due to continuous interaction but, rather, to migrations of farmers bringing with them the various components of

\footnotetext{
14 Adams and Adams, 1991, 60.

15 Adams and Adams, 1991, 54.

16 Buccellati 2007, 37.

17 Martino 2012.

18 Kökten, Özgüç, and Özgüç 1945; Alkım, Alkım, and Bilgi 1988; Thissen 1993; Bilgi 2001.
} 
the "Neolithic package" - a collection of technologies and beliefs that was once thought to be wholeheartedly and without exception adopted along with agriculture.

Svend Hansen's study Bildervom Menschen der Steinzeit is the most comprehensive of all recent diachronic studies of figurines and includes a discussion of all the known figurine types from western Europe to the Near East, from the Paleolithic to the Early Bronze Age. ${ }^{19}$ The figurine attributes listed in Hansen's typology are numerous and comprehensive, but they are not additionally utilized in a systematic analysis. Many of them, however, were used to create the attribute list compiled for the figurines in this study.

\section{Methodological Background}

In the interest of reducing subjectivity in their analyses, archaeologists and ancient art historians have used various methods from the statistical sciences. They have done so since the 1950s, but particularly since the 1970s, with the additon of the aid of computers. ${ }^{20}$ Archaeologists, however, first approached statistical methods through the lens of factor analysis in the late $1960{ }^{21}$ This type of analysis, which defined objects as a descriptive list of qualities, or "factors," allowed objects to be classified "automatically" rather than subjectively. ${ }^{22}$ Statistical analyses closely followed such factor analyses and will be described in more detail below.

We might then ask, why have these approaches not been used more widely? One explanation might be found in the battle over the use of statistical techniques to determine type in archaeology. These battles marked the arrival of "New or Processual Archaeology" and its staunch belief in the objectivity of its methods. This conflict is epitomized in the heated back-and-forth regarding the use of statistical methods between the archaeologists James Ford and Albert Spaulding in the early 1950s. The debate resulted from Spaulding's review of Ford's typological schema and Spaulding's promotion of statistical methods

\footnotetext{
19 Hansen 2007.

$20 \quad$ Spaulding 1953; Guralnick 1973; Bartel 1981; Hermon and Niccolucci 2002; Gansell et al. 2014, 194-205.

21 Factor analysis: a type of analysis that defines objects as a descriptive list of qualities, i.e., factors.

Hermon and Niccolucci 2002, 220.
} 
for the creation of archaeological types. ${ }^{23}$ While we will not put forward a new analysis of this general debate, as this has already been done elsewhere, below are a few of the most important quotes from this discussion:

Ford Response to Spaulding Article, February 1954:

Spaulding and some of his associates have been trained to prefer a stable finite world provided with tangible facts which, together with the logical truths that connect them, are all waiting to be discovered. This may make sense as a scientific ideal; I'm not too certain. However, "reality" is frequently confused with the ability of man to contact the phenomena with his five senses-a stone is real. Artifacts and observable situations are the "real" experienceable facts of archeology. Many cautious students have concentrated on these realities, thus hoping to avoid the risky business of stacking hypotheses into what may be a shaky structure...

The indiscriminate application of statistical formulas to archeological problems is not an activity of a cultural scientist.

Spaulding Response to Ford, April 1954:

Ford's objections to the ideas advanced in [my article] appear to revolve around (1) the notion that use of such techniques somehow constitutes a denial of continuous variation of culture in time and space and (2) certain implicit definitions of such terms as "artifact type" and "historical usefulness" which in effect make their use the exclusive prerogative of the archaeologist engaged in inferring chronology by ranking sites or components of sites in order of likeness as judged by relative frequency of attribute combinations. I shall attempt to show that the first objection is a gratuitous error and that the second is no more than a semantic quagmire.

Ford Response to Spaulding, April 1954:

First let me say that I am thoroughly sympathetic to all efforts toward development of more accurate methodology. But the application of statistics and other techniques to our problems, without regard for basic culture theory, cannot be regarded as an advance in technique...

Spaulding's suggestion that statistical analysis of the patterning to be found in a collection from a village site will establish pottery types useful in the study of culture history is amazingly naïve.

$23 \quad$ Ford and Steward 1954. 
Spaulding Response to Ford - April 1954:

The concept of reality, which Ford persists in rejecting, does not imply tangibility, stability, finiteness, or "a world filled with packaged facts and truths that may be discovered and digested like Easter eggs hidden on a lawn," as Ford asserts, but it does imply that the proper procedure for testing the truth is an appeal to the data of this external world.

As is clear from the quoted passages, the focus of the debate is on the real and experiential vs. the hypothetical and statistical. These are arguments that inevitably appear in relationship to the use of new technologies in archaeology. The arguments are suspicious of technology that could seemingly divorce oneself from the data to such an extent that the context of the data, and the knowledge that precedes the analysis, is superseded by the results of the analysis.

Although, to many of us, Ford's rejection of Spaulding's methods might seem out of place today, he is correct to remind archaeologists not to divorce their cultural knowledge from statistical analyses. It is thus unsurprising that Adams and Adams, who dismiss complete objectivity in typology creation, would also side with Ford. ${ }^{24}$ While the analytical techniques of statistics can hinder us due to the assumptions they make, they also help inform us of realworld complexities. That is why it is so essential that archaeologists with knowledge of the material either learn to do the analyses themselves or work closely in developing the technology. They must also reflect on the assumptions inherent in their work. Such reflection is admittedly not always readily available, nor is it always broadcast. ${ }^{25}$ That is why a volume such as this, with the intent to provide analyses and the background necessary to understand the methodologies, is so important.

As long as one remains careful about how one treats the data, statistical methods can be effective tools. Consciousness of the inherent subjectivity of one's typology can make the analysis of objects grouped in a typology all the more meaningful. Accepting a typology blindly, as some have done, without considering other outcomes for one's data, will not reveal the complexities of one's dataset. This has led some to emphasize the entanglement of artifacts and Marian Feldman in particular to move away from geographically defined styles to the notion of "communities of styles." ${ }^{26}$ As she has put it, "It is not just that these objects have resisted any straightforward or singular definition of

\footnotetext{
24 Adams and Adams 1991, 59.

25 Adams and Adams 1991, 60.

26 Entanglement is defined in Archaeology as the way in which all artifacts are interdependent and owe their existence-and, here especially, their visual appearance-to this interdependency and relatedness (Hodder 2012; Feldman 2014).
} 
meaning; it is also my sense that this very enchantment itself exists (and existed in the past) as an integral part of [an object's] material purpose." ${ }^{27} \mathrm{~A}$ typology then ought to reflect the mutable nature of an object.

While the ability of the method proposed here to capture this mutability is emphasized (see discussion section below), tried-and-true methodsparticularly multivariate analysis - are heavily relied upon to provide the backbone of the code. Multivariate analysis is one method often utilized by archaeologists to create typologies, but it is not simply one tool that is easily employed in the same way by everyone regardless of the purpose. It is, rather, a general description for a type of analysis that takes many forms. One must always adapt the method to the material that one wishes to analyze. Using a multivariate analysis, archaeologists can determine the types that define a typology through the analysis of multiple variables and their interdependency. Furthermore, such statistical methods were created for quantitative analyses and have traditionally placed more value on certain attributes of the archaeological artifact. Cluster analysis, ${ }^{28}$ a particular form of multivariate analysis that divides a dataset into groups based on how near the data points are to each other, gives one the ability to analyze subgroups of the dataset using an algorithm. ${ }^{29}$

Analyses of ancient figurines have often utilized multivariate analysis to elucidate connections between types of figurines. Saul Weinberg was the first scholar to use an attribute analysis in order to compare Neolithic figurines, though he did not use a computer. ${ }^{30}$ In 1968, however, Peter Ucko became one of the first archaeologists and art historians to utilize a computer-assisted numerical-attribute analysis. Ucko's study examined Neolithic anthropomorphic figurines from Egypt, Anatolia, and Greece, beginning with an analysis of the numbers of regionally affiliated attributes and proceeding to cross-cultural ones. ${ }^{31} \mathrm{He}$ argued against isolating specific figurine attributes for analysis and against considering unprovenanced material. ${ }^{32}$

Brad Bartel's 1981 article introduced a multivariate-attribute-analysis approach to the study of figurines that additionally correlated and measured the

$27 \quad$ Feldman 2014, 175 .

28 Cluster analysis: a type of analysis that divides a set of objects into groups (clusters) so that objects of one group are similar to each other, whereas objects within groups are dissimilar from the objects within other groups. See also in this volume, Monroe, 274-275, for cluster analysis applied to text analysis.

Algorithm: a step-by-step procedure for solving a problem or accomplishing some end, especially by a computer.

$30 \quad$ Weinberg 1951.

$31 \quad$ Ucko 1968, 427-444.

32 Ucko 1968, 390. 
strength of relationships among attributes. The attributes he included in his factor analysis were mostly stylistic, but they also included clay and posture. Logically, attributes found in all figurines or only in one were not included in his study because neither would illuminate relations between cultures. His list of attributes and his methodology constituted a starting point for the one used in Shannon Martino's study. Unfortunately, the program Bartel used in his study was not done on a modern computer and used punch cards, which are lost to us today.

In 1995 Peter Biehl used an attribute-analysis approach in his study of Gradešnitsa figurines c. 5000-4500 BCE in northwest Bulgaria in order to determine whether designs were chosen based on their location on the body of a figure. ${ }^{33}$ His interest in combining an analysis of the location of attributes with a description of those attributes informed much of the creation of Shannon Martino's database. What characterizes her study, and all these previous ones, is the large amount of data. Those of us who deal with the archaeological equivalent of "big data" are drawn to methods that naturally involve mathematical approaches necessitating computing power.

For the figurine analysis, Shannon Martino recorded the presence or absence of about 300 independent attributes that characterized the technological as well as the iconographic features of the figurines (Appendix 4.1). For example, under the heading "arm," there are 32 attributes that describe decoration, position, and modeling. Techniques of manufacture include features of surface treatment (e.g., slip, vertical burnishing, paint, or even fingerprints). By including so many attributes, Shannon Martino was able to consider a wide range of the possible traditions within figurine production and create a more nuanced typology that allowed significant clusters of features, both formal and technical, to emerge.

Rather than imposing any preconceived cluster of attributes, we developed a series of independent attributes. In this way, what might be viewed as a significant factor to us but not to the producer of the artifact would not be as heavily influential in the creation of a class. ${ }^{34}$ The subjectivity of this analysis will still be the subject of debate for anyone who disagrees. For example, someone might ask what might be considered a nose, or arms, but as long as the observer is consistent, there will be consistency in the assessment of what it means to have arms. Thus the name "arms" might not always be perceived as accurate, but what is identified as "arms" will be.

33 Biehl 1996.

34 Class here refers to an identified typological group, though group is the term used by the program for all possible classes that are output. 


\section{Project Methodology}

Matthew Martino was responsible for writing the code of the program in $\mathrm{C}++, 35$ and in the midst of collaboration, we discovered many difficulties in analyzing the qualitative data usually examined in regards to figurines. ${ }^{36}$ The program, therefore, was written in an iterative process. ${ }^{37}$ The goal was to create groups based on similarity, but determining how to gauge similarity required us to test the program several times to see what results various algorithms would produce. So a large portion of the development of the program consisted of refining and modifying the algorithms that it used to define groups. Eventually we settled on the procedure outlined below.

We used a hierarchical clustering algorithm that defined clusters (types) by considering how similar objects were to each other (in a quantitative fashion) and grouping "close" objects into the same type. The method that we used to determine how similar objects are is called metric scaling. This is done by considering each item as a point in a multidimensional space and calculating the "distance" between the points using a metric, just as one finds the distance between points on a map. As Torsten Madsen has noted, there is a problem with this method, namely that "the connection between objects and variables is broken...It is not possible to see the contribution of the individual variables to the analysis". ${ }^{38}$ This problem can, however, be overcome by an examination of the objects when the set of objects/the data is/are confined to a single item, such as figurines, pottery, or lithics. We also address this concern with the final output of the program, which makes the variables clearer by constructing a "representative" item based on the attributes of the items in a given cluster. Beside each attribute a number is given to indicate the likelihood that an object has a particular attribute in the identified group.

The creation of the typologies used in this study follows a consistent protocol. First, the two most similar objects are determined by the program based on the number of shared attributes. For the sake of the computer analysis, each qualitative attribute is given a number determining its presence or absence: 1 for present, $o$ for not present and .5 for unclear. Then one sets a difference parameter, that is, a number which defines the number of possible ways one

$35 \mathrm{C}++$ is a popular object-oriented programming language based on the older c programming language.

36 In this volume see also Bigot Juloux (162-163), who proposes a qualitative approach for text analysis.

37 For iterative process applied to text analysis, see in this volume, Monroe, 257, 266n25, 270.

38 Madsen 2007, <http://www.archaeoinfo.dk/> (accessed May 20, 2017), 2. 
object can differ from another. This difference parameter will be set somewhat arbitrarily at first, and then the program will be run multiple times with different values of the difference parameter to see how it affects the groups that are formed. Comparing quantitative information such as diameter is done by subtracting numbers and taking the absolute value of the difference, so that numbers like $12 \mathrm{~cm}$ and $12.75 \mathrm{~cm}$ are seen as $.75 \mathrm{~cm}$ different from each other, so $3 / 4$ of a difference parameter unit. This can lead to significant differences depending on the units of the measurement $(12 \mathrm{~cm}$ and $12.75 \mathrm{~cm}$ are $.75 \mathrm{~cm}$ apart, but also $7.5 \mathrm{~mm}$ apart), so an appropriate scaling weight can be used to adjust for this. An alternative way to deal with quantitative data like this would be to calculate the mean and standard deviation and replace one's measurements with the number of standard deviations they are from the mean, but this might introduce other problems. These problems would appear particularly when the underlying measurement data is not well fit by a Gaussian distribution (a bell curve) that has a central peak, is evenly distributed about the mean, and can be quantified with just the mean and the standard deviation (related to the width of the bell curve). Therefore we would recommend using an appropriate weight chosen based on the amount of variation in the data.

The two most similar objects are determined by finding how distant each pair of objects is from one another in the multi-dimensional attribute space using a metric. In this case we used the Manhattan metric for Boolean (for example, to indicate whether an attribute is present or not present) and qualitative data, which, as mentioned above, calculates distance by adding the absolute values of the differences of each attribute, as well as the familiar Euclidean metric for quantitative data, ${ }^{39}$ which takes the square root of the sum of the squares of the differences. In each case the value is scaled by the weight that one assigned the attribute. One could choose a different metric, but one advantage of a hierarchical clustering algorithm is that the choice of metric does not particularly affect the results. At most it will change the difference parameter necessary for different groups to appear. For example, imagine a very simple dataset with one qualitative attribute, color, and two quantitative, length and width. If we think the three attributes are equally important, the weights would be equal. If we had three objects, one (red, $2 \mathrm{~cm}$ long, $3 \mathrm{~cm}$ wide), another (blue, $5 \mathrm{~cm}$ long, $7 \mathrm{~cm}$ wide), and a third ( $\mathrm{red}, 2 \mathrm{~cm}$ long, $7 \mathrm{~cm}$ wide), the distance between the first two would be $1+\sqrt{ }\left(3^{2}+4^{2}\right)=6$, and the distance between the first and the third would be $0+\sqrt{ }\left(0^{2}+4^{2}\right)=4$.

39 Euclidean metric: the square root of the sum of the squares of a difference, the distance formula used in geometry. 
The two most similar objects form an initial core, and then one adds objects to the first two to create a type's core by adding all objects that differ from the two original objects by no more than half the difference parameter. This forms a distinct core of very similar objects for a group. Which objects are in the core of a group is tracked, so that an object that is in the core of one group is not in the core of any other group. We did this for two main reasons; one is purely practical, but the other is much more important. The purely practical reason for forcing the different cores to be distinct is that we wanted to make sure that the program did not just identify the same group over and over again. Secondly, and more importantly, this step reflects the belief that there are in fact distinct related groups in any given dataset where a bit of overlap is understandable (as will be shown in the next step), but the core defining aspects (and objects) of a group should be distinct.

The group is then filled out by adding all objects that differ from the core by no more than the total difference parameter, which can lead to overlap between different groups. After this pass, we have one more pass that adds objects that are within half of the difference parameter from any of the objects in the group. These last two passes add objects to the group as members, but not to the core, and so can be included in multiple groups. Then the group is complete, and the entire process is repeated until no two objects remain that are similar enough to create a core. Once no more objects are left to form a core, a final step is to get rid of groups that contain three or fewer objects, and then see if the objects from those cores fit into any other groups. This was done just to set a minimum size for a group, as a group that contains only two objects is not very illustrative. That said, the choice that a group needs to have more than three members is an arbitrary one that is easy to change.

In the end there remained some figurines which were too difficult to place into any single class, and thus they appeared in many groups. These are unavoidable outliers that appear clearly in the program output. This is actually an advantage of the program that is not typically found in typological analyses, which often restrict an object to its appearance in only one group. ${ }^{40}$ In this algorithm the only objects required to be in just one group are those that are part of a group's core. An obvious extension of the developed program that would help, in particular, to analyze the figures that fit into more than one group, would determine how well any given object fits into any given group, much in the way that Hermon and Niccolucci used referees and "fuzzy set the- 
ory" - the idea that an object may be "in between" belonging and not belonging to a set- to examine the subjectivity of typologies. ${ }^{41}$

The order of appearance of a group in the output of the program indicates the cohesiveness of a group, because the most similar pairs of objects are the first to be identified. Thus every successive group is more diverse than the first, giving the program user an indication of diversity as well as allowing them to quickly examine various possible typological outcomes.

The number of groups created when following this protocol is directly dependent upon the difference parameter. Objects in a group cannot differ from at least one other object by more than the difference parameter. This does not mean that all objects have the same shared attributes, but, rather, that a cluster is formed by finding objects that are sufficiently close to the core in the space of all possible attribute values. When the difference parameter is decreased, objects will be more similar; when the difference parameter is increased, less similar items will be placed together. It is the degree of similarity that creates the groups, and, remarkably, for different values, there are distinct defined groups. This is remarkable in that one might assume that this method would result in the collection of all objects into the same group, and, for a high enough value, this would happen. Even for a difference parameter as high as 12, as was used with the figurines, however, not all fell into the same group. Another interesting consequence of looking at the groups formed with different difference parameters is that subgroups can be identified inside larger groups, while with a low difference parameter several groups are distinct; as the difference parameter is increased, objects merge to form larger clusters. Finally, for figurines, especially ones as fragmentary as we had, we had to run three separate sets in order to determine the best classes, one for the top, one for the middle, and one for the bottom sections of each figurine.

The results were designed to be output from the program using unique identifiers (ID) for each object, so that those identifiers could then be searched for in one's database to easily identify groups ${ }^{42}$ especially when the database includes images or other additional identifying information. Along with the list of objects found in each group, a list of average attributes is compiled so as to better define and refine that group. Since we do not prohibit objects from appearing in more than one group, using these average descriptors also has the advantage of helping one to identify points of comparison with other classes

\footnotetext{
41 Hermon and Niccolucci 2002, 225.

42 Identifiers (ID) are simply unique numbers that do not have a specific meaning. Their quality resides in their uniqueness. See also in this volume, Pagé-Perron (196, 206-208), who has developed a database in Structured Query Language (SQL).
} 
when one object fits into two classes. In addition, these average attributes can be created from either the complete class or just the core group. These average attributes can also be used to determine which group any given object would best fit into if it did not get assigned to any group originally. This can be done by finding the distance between the representative objects and the objects of interest; the distance between the average and the object is an indicator of how well it would fit into that class. An alternative way of doing this is to calculate the distance between the object and each of the objects in the core of each group, then divide that total distance by the number of objects in the core. This method, however, is functionally equivalent to the other method.

This list of average attributes also helps to validate the clustering procedure by allowing one to compare the figurines that supposedly fit the cluster/group to the list and see how closely they fit. Additionally, the percentage of figurines in the cluster that can be associated with each attribute can be obtained, and a threshold can be set for the number of attributes an object must have in order to be included. The cluster can further be checked by the visualization of each figurine within the cluster. We were able to do this easily because FileMaker allows one to associate images with data and output them together. Such essential evaluative procedures were outlined by Mark Aldenderfer in his review of cluster analyses as used by archaeologists. Those procedures were essential to understanding the results of the analysis outlined below. ${ }^{43}$

\section{Smaller Figurine Case Study}

For the comprehensive results of the program, one may look to Shannon Martino's dissertation, ${ }^{44}$ but for a more detailed analysis of the program's application and the possibilities it affords through multiple analysis, this work must focus on a small portion of the larger dataset. Because one of the most robust local figurine studies is the work of Julia Obladen-Kauder at the site of Demircihüyük, ${ }^{45}$ these figurines were chosen as a case study.

Demircihüyük is located in northwest Turkey near modern-day Eskişehir, and although it has remains from the Neolithic to the second millennium BCE, the study detailed here was focused on the Early Bronze Age figurines from the

\footnotetext{
43 Aldenderfer 1982.

44 Martino 2012. For another approach of cluster analysis applied to quantitative methods for inter-textual relations on cuneiform texts, see in this volume, Monroe, especially 274.

45 Obladen-Kauder 1996, 209-314.
} 
site, which are dated c. $3000-2500$ BCE based on four radiocarbon dates. ${ }^{46}$ The site is about 8om in diameter and was first excavated in 1937 by Kurt Bittel. Manfred Korfmann directed excavations at the site between 1975 and 1978. During the Early Bronze Age, the site had a cemetery as well as a settlement and was radially planned with a circular layout of abutting, single-storied, trapezoidal buildings and a fortification wall with four gates. ${ }^{47}$

To determine the meaning of the Demircihüyük figurines, Obladen-Kauder analyzed their form, details, and material. She believed that the figurines were not obviously part of a cult or religion, stating that it is not compelling to conclude either that the sexual characteristics of figurines were meant to be lifegiving, or that they were assigned to a goddess or ritual. ${ }^{48}$ She insisted, rather, that they must somehow be associated with femininity.

Unfortunately, the contexts of the figurines are not entirely clear. Of the approximately 200 figurines found in the settlement, 116 come from secure contexts, but little is known about those contexts except that 78 came from interior courtyards, 23 come from the foremost rooms in a structure, and ten come from the back room of one building presumed to be a domestic structure $^{49}$ Additional figurines were found in the associated cemetery of Demircihüyük-Sarket, in the graves of both adults and children. Some of the graves contained up to three figurines. ${ }^{50}$

Obladen-Kauder argues that the Demircihüyük figurines are a local development relying on three observations: there are a large numbers of figurines; their stylistic development seems to take place locally without big jumps in either form or decoration; and several stylistic types from surrounding areas are combined in them. ${ }^{51}$ The results of the large-scale analysis confirms her theory of the local development of the type, given that almost all of the figurines from the site fit into the same types. In addition, the subtypes within those types are almost exclusively filled with figurines from Demircihüyük, rather than from any of the more than 30 other sites examined in the study.52

When analyzing all the figurines in the corpus, the program divided the figurines from Demircihüyük into four major types. Most fit into what Shannon Martino called "Class I" and "Class XIII" in her broader analysis of figurines

\footnotetext{
$46 \quad$ Korfmann and Kromer 1993, 139-140.

47 Korfmann 1983, 216-217, 242.

48 Obladen-Kauder 1996, 257-258.

49 Obladen-Kauder, 1996, 273.

$50 \quad$ Seeher 1992: fig. 7·3-4; Aydıngün 1999.

$51 \quad$ Obladen-Kauder 1996, 279.

52 Martino 2012.
} 
from the region. It is interesting to note that these figurines were distinguished primarily by posture and the elaborateness of headdress. Class I will be the focus of the analysis in this article. This is by far the largest of the classes, and it is also the class about which more has been written than had been written about almost any other, particularly those that are considered of the Violin Idol type. ${ }^{53}$ Figurines in this class are characterized by a circular head, stump arms, and either a semicircular bottom or articulated legs. The faces of each figurine are distinguished by a nose shaped through pinching or modeling. Slightly over $70 \%$ of the figurines from Demircihüyük are made from a fine clay, and only $10 \%$ are unfired. ${ }^{54}$ Fifteen of the heads assigned to Class I come from good contexts in layer $\mathrm{H}$ of Demircihüyük, placing them in the Early Bronze I phase of the site. ${ }^{55}$ They are also concentrated in layers $\mathrm{K}_{1}$ and $\mathrm{K}_{2}$ and $\mathrm{L}$ and $\mathrm{M}$, which gives a rough end-of-use date of the beginning of Early Bronze II. ${ }^{56}$ The attributes held most in common by figurines in this class are as follows:
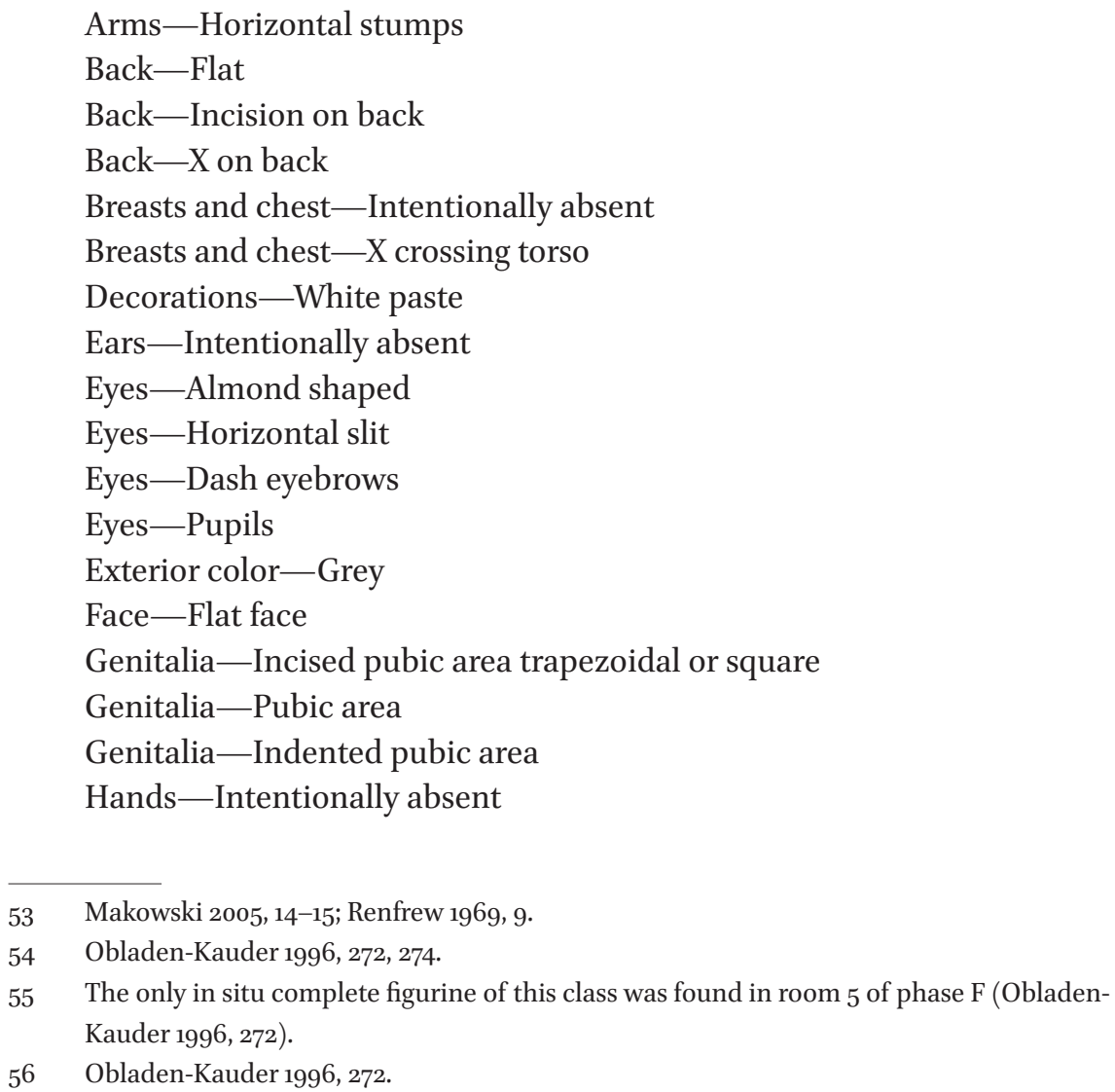


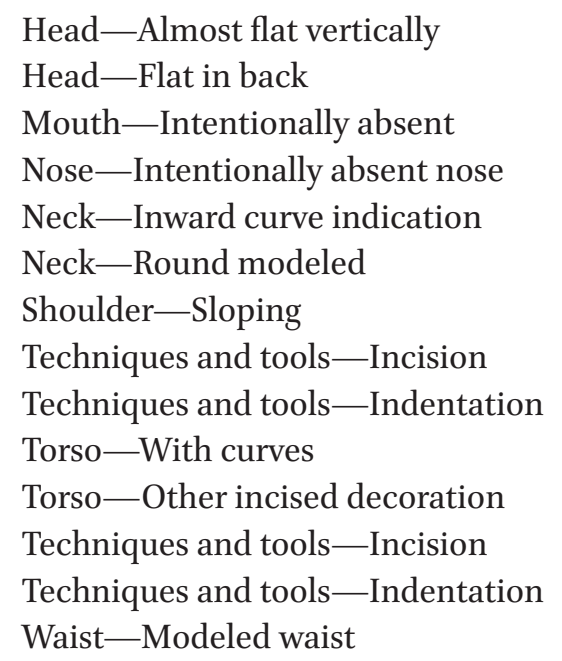

The following is a description of the results of the computer analysis when just the figurines from Demircihüyük were examined. Using a difference parameter of two on the figurines from the site of Demircihüyük, three bottom groups are defined. Figure 4.2 indicates the members of one of the cores for the bottoms that were defined.

When the difference parameter is increased to four, middle groups begin to appear among the Demircihüyük assemblage (Fig. 4.3).

Two top groups also appear at four, but these groups have only two figurines in their core groups due to the increased diversity of the facial features. For example, it is not until a difference parameter of eight that heads with a headdress appear, and then only one version of them. This analysis shows that the top sections are more diverse than the bottoms or middles in their design, especially given that the number of attributes for the top, middle, and bottom are similar at 85,98 , and 59 , respectively. This means that the number of attributes vary by less than a factor of two, but the difference parameter required to have a group varies by a factor of three (See Appendix 4.2 for the attributes run for this site listed by section of the body). Moreover, the number of possible attributes for the middle is slightly larger. Lastly, the number of members in a group grows as one increases the difference parameter, allowing one to define subclasses based on classes and to see how some classes blend into each other and are more closely related than others.

One possible conclusion is that greater attention was given to, or license allowed, for the heads at Demircihüyük, especially for the facial features. The results of the analysis suggest that the primary marker of this class for the bottom section is posture, for this distinguishes the classes from each other. 
Though many subclasses appear as the difference parameter is decreased, as the difference parameter is increased, these attributes quickly begin to become irrelevant, while seated figurines remain in an entirely separate class.

\section{Ceramics Case Study}

Just as with the figurines, the ceramic data from the western Anatolian site of Demircihüyük, we thought, was worth pursuing because it had been robustly published. ${ }^{57}$ In order to work with a smaller dataset, around $5^{0}$ examples, the case study was limited to the forms of cups and bowls from Early Bronze Age levels H-M (Fig. 4.4).

These vessels varied in color from red to brown, both in terms of their slips as well as their internal fabric colors. ${ }^{58}$ Their inclusions varied from fine to large, ${ }^{59}$ from slate to fine clay with no inclusions to mention. The surface treatment varied from highly polished to unpolished. While such variety could have afforded one with 100 attributes, the 11 attributes which were chosen for analysis were based not on a new assessment of the material, but, rather, on an analysis of how Jürgen Seeher organized his cups and bowls into Forms. This was done even though archaeologists sometimes classify pottery by the components of the clay firstly and by the form second (Appendix 4.3). Based on analysis of the vessels' descriptions within the text, as well as in the catalog, Seeher seems to have created types based solely on form, to the exclusion of handle types; decoration and fabric were not considered. Therefore, in the new analysis, information about the presence of a handle was weighted less than all the other attributes. Our goal was to come up with the exact same groups, the major difficulty being that the Demircihüyük publication does not have entirely consistent descriptions of the forms, so determining the attributes of each form was difficult.

For example, the images in Figure 4.5 are to scale, and what distinguishes bowl from cup is not entirely clear, except that perhaps handles of the type depicted may preclude pieces from being cups. Therefore, form 6 can have such a horizontal handle, or it may not. Other problems include interpretations

\footnotetext{
$57 \quad$ Seeher 1988.

$5^{8}$ Slip: a mixture of clay and water poured or brushed onto the surface of pottery before firing, used to create a smooth coating of possibly another color than that of the clay that comprises the body of the vessel. Inclusions: usually pieces of rock found deliberately or unintentionally mixed into the clay of a vessel.
} 

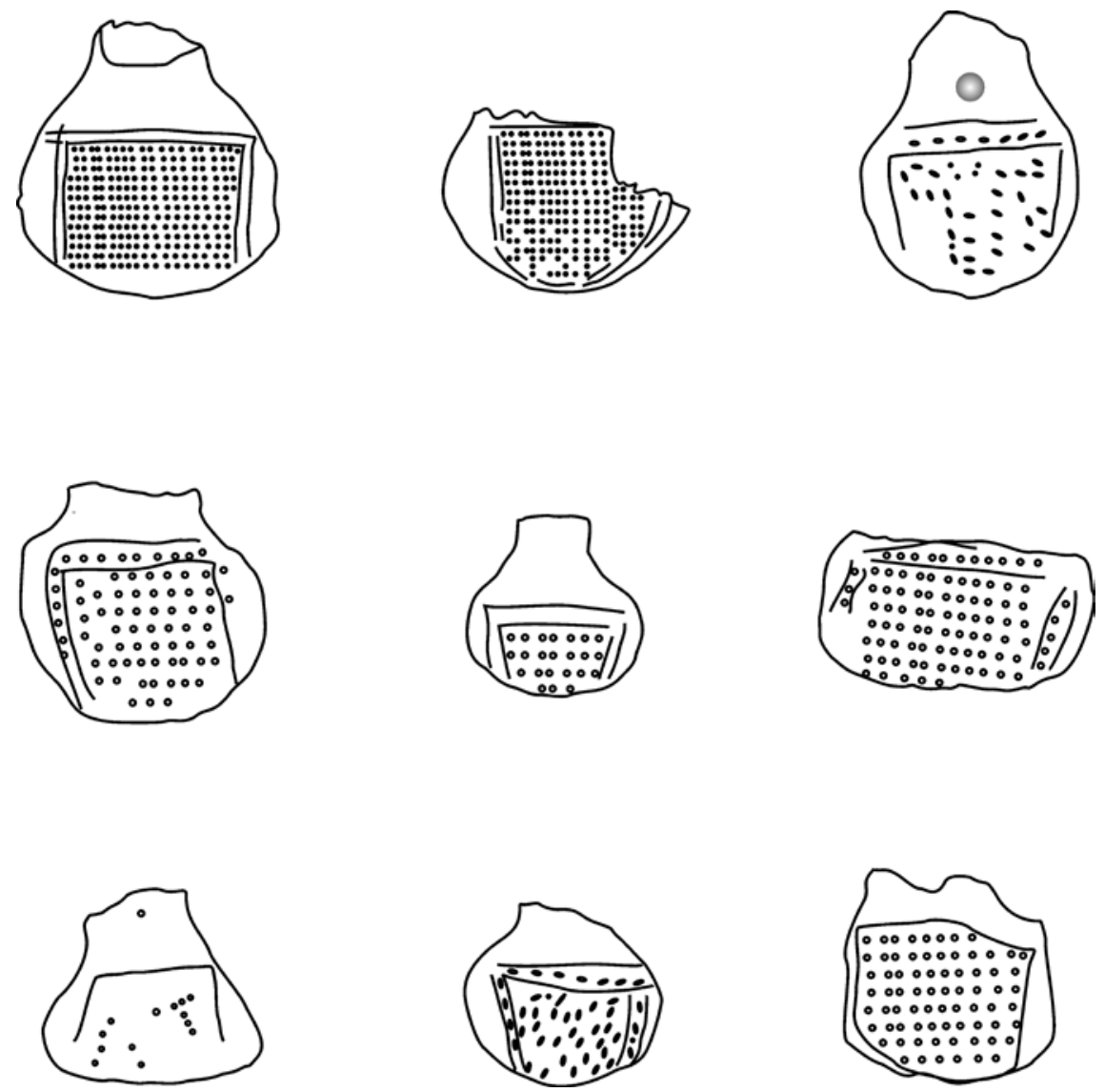

FIGURE 4.2 Example of core defined for Demircihüyük bottom section (images adapted from Obladen-Kauder 1996: pls. 114.2-3, 114.5, 114.7, 115.3-5, 115.7-8)
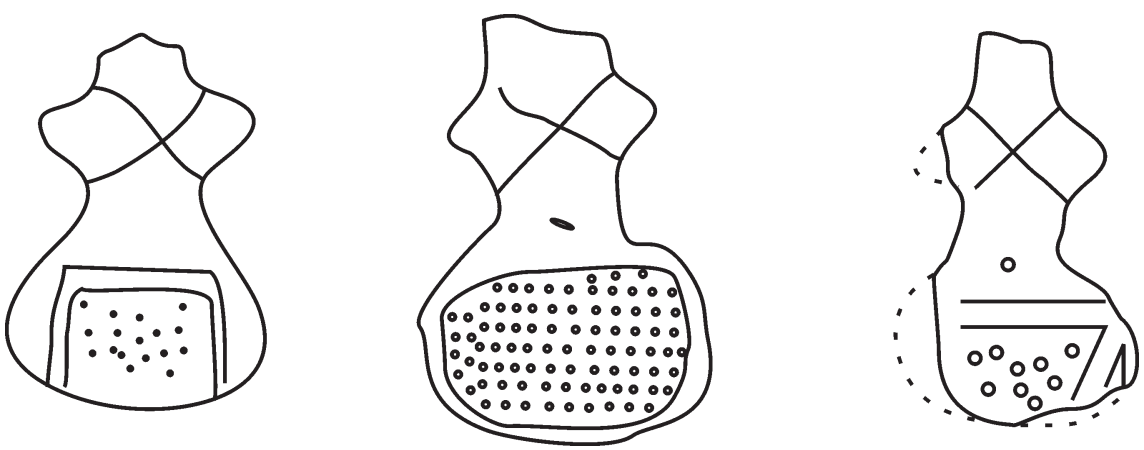

FIGURE 4.3 Example of core for Demircihüyük middle section (images adapted from ObladenKauder 1996: pls. 115.10, 116.3-2) 


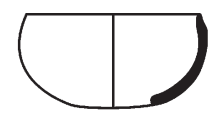

Form 3

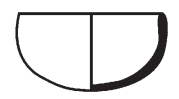

Form 4

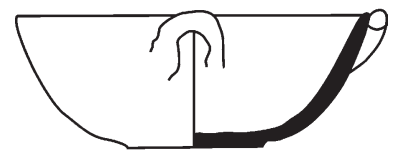

Form 5

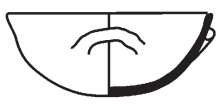

Form 6

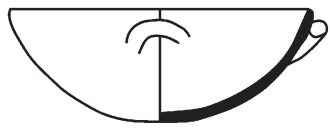

Form 7
FIGURE 4.4

All forms captured by analysis (images adapted from Seeher 1988)

of the rim angle, which were difficult to make based only on drawings in a book. The rim angles might be very slight, and it is not clear in those instances what designation the author might have chosen to give the vessel, as the designation is not spelled out in every vessel description. Given that, all the groups were fairly consistent in the output.

At a difference parameter of four, the program output 11 valid groups. Six groups were eliminated for being too small, so the group numbers go from o to 16. Table 4.1 represents groups that had some of the least correlation with Seeher's forms.

The first group is composed of vessels of form $5^{-7}$, with the average description being an everted rim, a height-to-diameter ratio of .415, a height of $5.8 \mathrm{~cm}$, a diameter of $13.5 \mathrm{~cm}$, with roughly $75 \%$ having a handle. This is consistent with the fact that, for Seeher, all three of these forms could be considered cups 
TABLE 4.1 Groups unlike Seeher's forms.

First group Sixth group

§Group number: o with 4 members

§Core: pl.2.5 pl.2.12 pl.2.14 pl.18.11

§Members:

§Average member:

§Height: 5.8125

§Diameter: 13.5

§Handle: 0.75

§HeightDiameterRatio: $0.43055^{6}$

§WidthCenterBody: 12

§Vertical Rim: o

§Inverted Rim: o

§Everted Rim: 1

§Angled Rim: o

$\S$ S-Shaped Profile: o

§Semicircular Handle: o

§pout: o
§Group number: 5 with 4 members

§Core: pl.18.7 pl.28.5

§Members: pl.1.10 pl.18.8

§Average member:

§Height: 6

§Diameter: 12.75

§Handle: 0.5

§HeightDiameterRatio: 0.470588

§WidthCenterBody: 12

§Vertical Rim: 1

§Inverted Rim: o

§Everted Rim: o

§Angled Rim: o

§S-Shaped Profile: 0

§Semicircular Handle: o

$\S$ Spout: o
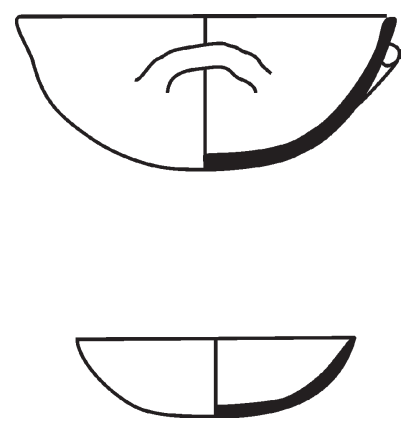

FIGURE 4.5

Variations of form 6 (images adapted from Seeher 1988)

or bowls and for the most part had everted rims. The sixth group that appears is composed of vessels in cup form 3,4 , and 6 , with an average height of $6 \mathrm{~cm}$, diameter of $12.75 \mathrm{~cm}, 50 \%$ handles, height-to-diameter ratio of .47, and a vertical rim (Fig. 4.5).

All of these forms have a diameter consistent with one another, which may explain their overlap here. 
TABLE 4.2 Groups that best fit with Seeher's forms.

Fifth group Eleventh group

§Group number: 4, with 4 members

§Core: pl.19.7 pl.19.10

§Members: pl.2.6 pl.19.6

§Average member:

§Height: 6

§Diameter: 15

§Handle: 0

§HeightDiameterRatio: 0.4

§WidthCenterBody: 12.75

§Vertical Rim: 1

§Inverted Rim: o

§Everted Rim: o

§Angled Rim: o

§S-Shaped Profile: o

§Semicircular Handle: o

§spout: o
§Group number: 10 with 4 members

§Core: pl.2.10 pl.19.8

§Members: pl.2.20 pl.19.21

§Average member:

§Height: 6

§Diameter: 17.25

§Handle: 0

§HeightDiameterRatio: 0.347826

§WidthCenterBody: 14.625

§Vertical Rim: 0

§Inverted Rim: o

§Everted Rim: 1

§Angled Rim: o

§S-Shaped Profile: o

§Semicircular Handle: o

§pout: o

Table 4.2 represents the groups that fit best with Seeher's forms. Of the 12 defined groups, five of them had at most only one extra member, i.e., all but one vessel belonged to the same vessel form. The fifth and fifteenth groups were composed of vessels of cup form 6 only. For the fifth group, vessels had an average height of $6 \mathrm{~cm}$, diameter of $15 \mathrm{~cm}$, a height-to-diameter ratio of .4, and a vertical rim and no handles. This too is consistent with Seeher's description of form 6. For the fifteenth group, the average height was $7.1 \mathrm{~cm}$, diameter 18 $\mathrm{cm}$, height-to-diameter ratio of .40, and an everted rim and no handles. The eleventh group was composed of vessels mostly of cup form 7 , with one of form 6 with an average height of $6 \mathrm{~cm}$, diameter of $17.25 \mathrm{~cm}$, height-to-diameter ratio of 0.35 , and an everted rim. Therefore, this group, too, is consistent with Seeher's analysis of form 7 , but with a slightly larger average diameter than the second group.

Despite the fact that there is some overlap in the forms, the average descriptors of the forms as indicated by the program show that they are consistent with the descriptions of the forms given by Seeher. It seems that where the results do not exactly match Seeher's forms, something has been missed from 
Seeher's methodology to define forms, or too much or too little weight has been given to a particular attribute. And, of course, as mentioned above, the rim angle is difficult to determine from a book. A last note, none of the "bowls" fit into a group until a difference parameter of 8 , which seems to confirm the validity of Seeher's typological systems that placed no more than four bowls into any one type and made them a more diverse lot. Ideally this study could also be compared to an extensive reanalysis of the pottery from Demircihüyük.

\section{Why This and Not Another?}

This program uses an agglomerative hierarchical clustering algorithm. It is agglomerative because all objects start in their own cluster, then get grouped together as the program progresses. Another way that this could be done would have been to put all objects into the same cluster to start with, then make cuts and divide it into smaller and smaller clusters. In some sense, when the program is run with different difference parameters, one gets some of the aspects of both methods; with high difference parameters one gets a few, large clusters, and with low difference parameters, one gets many, small clusters. This is also the sense of the word "hierarchical" here, as with varied difference parameters, one gets a sense of how the different clusters are related to each other. Some clusters are subclusters of other clusters, as is apparent when the difference parameter is varied and the results analyzed.

There are several advantages to the algorithm developed here. One is that no assumptions need to be made about the distributions of the underlying dataset. Using probabilistic methods, one must make assumptions (priors) about the distributions of the different attributes amongst all the possible objects; for example, a common distribution is the familiar Gaussian distribution. This is a reasonable assumption, as many things tend to follow a Gaussian distribution; for example cooking pots in a kitchen have an average size and tend to vary consistently around the average size, with some above and some below. If we considered all the plates in a house, though, the distribution would be multimodal, with several peaks in frequency, for dessert plates, dinner plates, and serving plates, each with its own corresponding bell curve. Different priors can be considered and optimized for the creation of groups, but no such assumptions need to be made to use this method. The most similar concern this method introduces is in the choice of weights and attributes, but these assumptions are explicit in the program.

As mentioned above, another advantage of this hierarchical method is that one can see how clusters are related to each other by looking at how they 
change when the difference parameter is changed. Clusters formed with a higher difference parameter tend to be more heterogeneous, and they fragment as the difference parameter is decreased. For particularly diverse datasets, those with many unique or uncommon attributes, the difference parameter may need to be quite high before all the objects end up in the same cluster, but this natural breakdown of cluster and subcluster-defined by lower effective difference parameters - is one advantage of this algorithm.

One more advantage of this method is that it is similar to the process that would be followed by a person creating a typology, just significantly faster (as an example, with a dataset of 2000 objects and 285 attributes, runtimes were in the several-minutes range). Some multivariate analyses can be very opaque, producing an output that does not explain how that output was achieved and giving no direct understanding of what the output means. One example is the work done by Bartel on figurines (1981) that made little mention of how they program he developed actually worked. With the algorithm explained here, one can easily output the cores of each cluster so that they can see the set of objects that formed the basis of the cluster. In addition, because one can generate representative objects for each cluster, one can determine, with some certainty, why each object was placed in each cluster. The method is objective in that it depends only on the attributes that have been chosen and the weights that have been assigned. Varying the difference parameter and looking at the resulting subclusters makes it more evident how each cluster was formed and where it stands in relation to its subclusters and superclusters; the latter is defined by the largest effective difference parameter. This is information that would be explicit to the scholar creating a traditional typology, though perhaps not explicitly formulated in the publication of the data, and it is nearly as explicit in this method.

Although it is an advantage to have complete personal control of these aspects of the process, a major disadvantage relative to a traditional typology is that while the program creates clusters and representative objects, and the core of each cluster can be output, the actual importance of each attribute to the cluster can be difficult to determine. A frequency analysis of the attributes of objects in a cluster clarifies how many objects in a given cluster have an attribute, for example, but it cannot explain which attribute(s) were the necessary components of the cluster. One can infer this by looking at subclusters and superclusters, as well as their representative objects, but, in a handmade typology, one would have a complete understanding of why each type is the way it is.

The following is a pseudocode snippet of the program advocated here: 
best $=$ threshold; $/ / 60$ The threshold is the difference parameter for this run

for ( $i=0 ; i<$ number of $i t e m s ; i++) / / T h i s$ loop runs through all of the items in the dataset

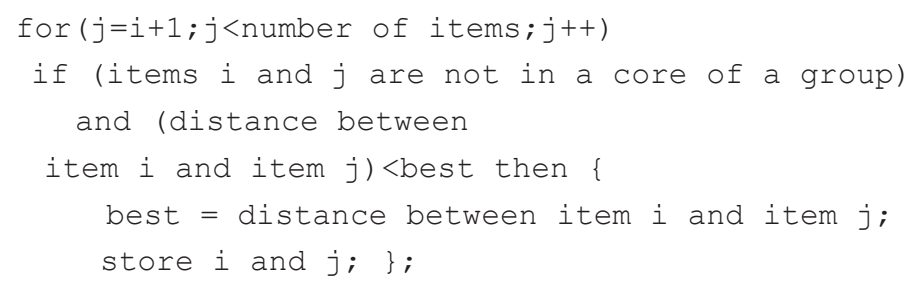

//Now $\mathrm{i}$ and $\mathrm{j}$ are the two closest objects that are not already in the core of a group

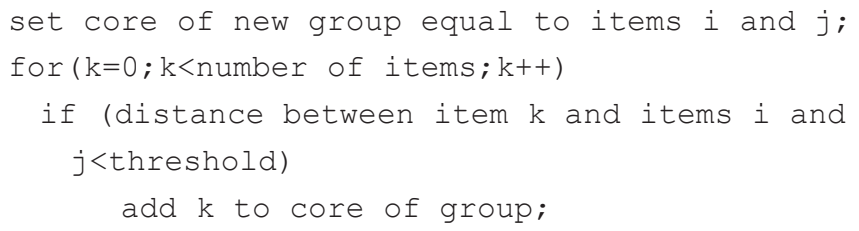

//Then the core of the group is complete, now add items that can be in multiple groups

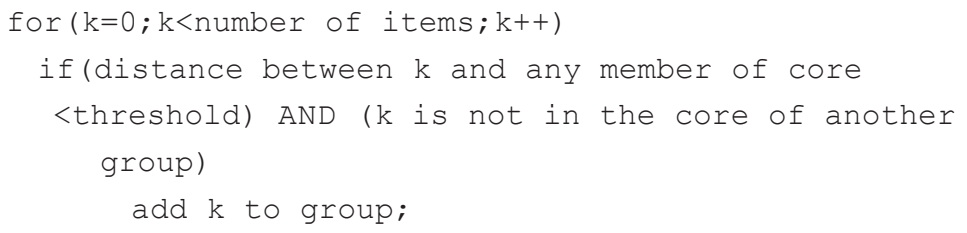

// Finally, one more pass of adding items to the group; these can be similar to any member of the group, but they must be more similar than in the previous step (the difference threshold is cut in half)

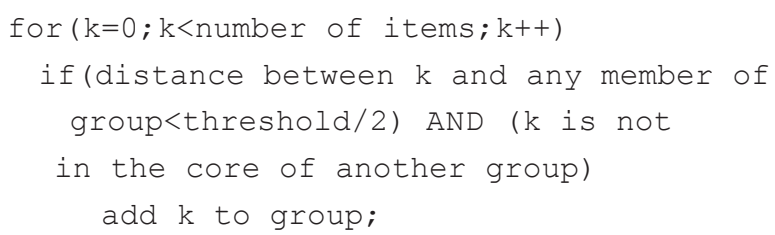

//Now the group is complete

6o "//" indicates a descriptive comment and is not in the program itself. 


\section{Discussion}

The groups defined by the computer analysis are cohesive, but, as mentioned earlier, there are outlier objects that tend to appear in all the groups, due to the simplicity of their form or their uniqueness (often fewer than three examples in the database). This situation is allowed in the analysis so as not to exclude any object from a group simply because it has already appeared in another group. This was made particularly clear in the large-scale analysis of the figurines. Such objects have to be dealt with on a case- by-case basis, and the results of the analysis must be examined for clarity.

Some objects can have too few attributes to be easily found by the program, as extremely incomplete fragments will be distant from all other objects. Really simple objects, even when complete, tend to be less distant from other objects when the number of attributes is large. This is because when the number of attributes is very large, most objects will not have most of the possible attributes, so simple objects tend to appear in many groups. These, therefore, ought not to be recognized as part of any group except the one in which they are the predominant type.

If one does not collect consistent data, then the groups produced by the program will not be consistent. That is to say, if one's definition of "arm" varies from object to object, then the results from the program will not be very useful.

Some missing information is unavoidable when working with fragmented artifacts, but a lot of missing information means that one will have to do more interpretation of the results. Others have addressed this problem of missing information by limiting their variables. ${ }^{61}$ While this is a perfectly acceptable solution, it does risk not recognizing significant distinctions between objects. One way in which we tried to overcome this problem was by indicating when it was unclear whether an attribute was present or absent, and also by indicating positively when an attribute was not present. As stated above, we also analyzed figurines in groups that accommodated the usual parts in which the fragments are found, that is, head, torso, and lower body. Obviously, for different analyses different accommodations will have to be made.

The types defined may not be the ones expected. This is when one finds out if one "told" the program what was important, or if one left something out, or if one told the program information that was not important, but that information defined groups anyway. A program's ability to be flexible and to be run quickly is thus essential to any typological analysis.

$61 \quad$ Gansell et al. 2014, 198. 
To use the program, all one needs is a set of attributes, a database of their objects (that can be exported to Csv format), ${ }^{62}$ and a set of weights that describe how important each of the attributes will be in the formation of groups. One must specify along with the weights whether the attributes are Boolean, quantitative or qualitative, and one needs to specify an initial difference parameter. All of these options are easy to change, and the program runs in minutes for datasets of several thousand objects, so there is little risk in choosing somewhat arbitrarily and then refining one's parameters. Such options need to exist because although this is a tool meant to remove subjectivity and ease the understanding of large amounts of data, that data is best and properly understood by those who study it. You as a scholar understand the significance of certain aspects of an object and the unavoidability or universality of others, and you are the one to gather the data and therefore understand the meaning of your descriptive terms. It is the responsibility of all scholars to gather data well, both comprehensively and responsibly.

\section{Appendix 4.1. List of Figurine Attributes}

Arms

Horizontal stumps

Rounded stumps

Downward pointed stumps

Upward pointed stumps

Freely modeled

Applique arms

Relief modeled

Created by incision

On chest below breast

On chest beside breast

In back and front center

To the side of abdomen

Between breasts and touching

On abdomen

Meet at center of torso

One up, one down

On thighs
Down at sides

Raised straight above head

Bends elbow and reach down out to sides

Bends elbow and reach up out to sides

Folded

Crossed

Curves/Bow down to torso

Reach forward

Intentionally absent

Holes at end

Pierced through upper arm

Indentation on back of elbows

Incised decoration

Indentation

Aprons

Incised

Indented

62 CSV stands for Comma Separated Values. It is a format that most programs can interact with given the simplicity of its formatting and coding. 
Back

Flat

Rounded

Bump on back

Incised spine

Modeled spine

Spine indicated

Cavity/Hood

$\mathrm{X}$ on back

Indentations

Incision across top

Indentations across top

Incision on back

Ribs

Breasts and Chest

Round breasts

Modeled breasts

Pendulous breasts

Triangular breasts

Applique breasts

Indented breasts

Asymmetrical

Unlevel breasts

Indented nipple

Intentionally absent

Indented decoration across top of chest

Incised decoration across top of chest

$\mathrm{X}$ crossing torso

Bolero vest

Buttocks

Moderate protusion

Vertical line as division

Modeled

Horizontal line below

Incised circles

Indents

Horizontal hole in hip

Hollow
Chin

Modeled chin

Ceramic matrix

Coarse

Fine

Mica in surface

Visible organic temper

Digits

One incision for toes

Three incisions for toes

Four incisions for toes

Five incisions for toes

Modeled toes

Two incisions for fingers

Three incisions for fingers

Four incisions for fingers

Five incisions for fingers

Modeled fingers

Incised wedge-shaped fingers

Decorations

Obisidian inlay

Red paint

White paint

Yellow paint

Red paste

White paste

Ears

Incised ears

Pinched ears

Applique ears

Modeled ears

Indented holes

One piercing

Two piercings

Three piercings

Four piercings 
Five piercings

Six piercings

Seven or more piercings

Earrings

Intentionally absent

\section{Exterior Color}

Pink

Brown

Red

Orange

Beige

Yellow

Grey

Speckled

Black

Eyes

Socket area impressed

Almond shaped

Semicircular

Diagonal slit

Horizontal slit

Applied or relief oval

Applied circle

Circular incised

Indented

Pierced through

Modeled eyes

Modeled eyebrows

Dash eyebrows

Straight eyelids

Rounded eyelids

Pupils

Intentionally absent eyes

Face

Flat face

Modeled and round

Intentionally absent
Comes to point at nose

Feet

Incised decoration of footwear

Roughly foot shaped

Flat disc shaped

Genitalia

Modeled penis

Modeled female pubic area

Incised pubic triangle

Incised pubic area trapezoidal or square

Pubic area

Indented pubic area

Circular pubic area

Vagina indent

Vagine incised

Hole under rear end

Head

Incisions to indicate hair or headdress

Hole in top of head

Hole vertical through neck

Cylindrical

Roughly spherical

Triangular

Upside down conical head

Rectangular

Circular

Pinched stump

Stump with rounded point

Almost flat vertically

Hollow

Flat in back

Inclined back

Concave head

Modeled forehead

Flat headdress

Floppy headdress

Rounded headdress or back of head 
Conical or slightly pointy headdress

Hait, hairbun, or pigtail

Intentionally absent

Hands

Both on breast

One on breast

One between breasts

Neither on breast

On belly

Intentionally absent

Made through incision

Interior color

Brown

Dark brown

Dark grey

Orange

Pink

Grey

Legs

Semicircular base

Ovoid base

Cubical base

Indicated with modeling

Indicated with incision

Circular base

Conical base

Cylindrical base

Concave base

Square base

End in point

T-shaped base

Incised decoration

Indented decoration

Formed separately

Hole vertical through center of leg

Separated

Bent at knee
Bent at hip

Modeled knee

Applique knee

Knee indicated with incision

Modeled shin

Ankle area protusion

Incision above knee

Intentionally absent legs

Mouth

Line of indentations to indicate

Single indentation

Slit

Semicircular mouth

Circular incised mouth

Modeled mouth

Indentations below

Dashes below

Intentionally absent

Nose

Pinched

Incised

Modeled non-beak

Modeled beak

Indented nostril hole(s)

Intentionally absent nose

Pierced nostril hole

Modeled from top of head

Horizontal hole in nose

Neck

Inward curve indication

Elongated neck

Round modeled

Dot decoration

Horizontal hole through

Applique decoration

Incised decoration

Non-centrally placed 
Navel

Vertical hole through belly

Horizontal hole through belly

Indentend navel

Fingernail navel

Incised navel

Protruding navel

Protruding circle around navel

Position

Seated

Standing

Leaning backward

Leaning forward

Quality of Finish

High burnish

Burnished

Stripe burnish

Wiped

Polished

Evened out/smooth

Red slip

Cream slip

Brown slip

Black slip

Beige slip

Slip

Shoulder

Sloping

Straight

Square

Indented decoration
Torso

Cylindrical torso

Roughly rectangular

With curves

Conical

Incision or indentation in middle of chest

Diagonal incised band with dots

Other incised decoration

Applique decoration

Hole through center of top

Hole through center of bottom

Belly

Cavity in area

One side bias

Techniques and tools

Fingernail impressions

Evidence of copper

Incision

Indentation

Impression with wedge shaped tool

Short stabs

Drill marks

Hollow body

Incisions/Piercing after firing

Core first construction

Fold construction

Finger impressions

Waist

Modeled waist

Love handles

Incision at waist distinct from pubic area 


\section{Appendix 4.2. Attribute Lists by “TopMiddleBottom”}

Top

C_Modeled Chin, 1, 1

E_1xPierced, 1, 1

E_2xPierced, 1, 1

E_3xPierced, 1, 1

E_4xPierced, 1, 1

E_5xPierced, 1, 1

E_6xPierced, 1, 1

E_7X or more Pierced, 1, 1

E_Applique, 1, 1

E_Earring(s), 1, 1

E_Incised Ears, 1, 1

E_Indented holes, 1, 1

E_Intentionally Absent Ears, 1, 1

E_Modeled, 1, 1

E_Pinched Ears, 1, 1

Ey_Almond Shaped, 1, 1

Ey_Applied circle, 1, 1

Ey_Applied or Relief Oval, 1, 1

Ey_Circular Incised, 1, 1

Ey_Dash Eyebrows, 1, 1

Ey_Diagonal Slit, 1, 1

Ey_Horizontal slit, 1, 1

Ey_Indented, 1, 1

Ey_Intentionally Absent Eyes, 1, 1 A_One up one down, 1, 1

Ey_Modeled Eyebrows, 1, 1

Ey_Modeled Eyes, 1, 1

Middle
A On chest beside breasts, 1,1

A_On Thighs, 1,1

A_Applique Arms, 1, 1

A_B/t breasts and touching, 1, 1

A_Bends elbows \& reach down out to sides, 1,1

A_Bends elbows \& reach up out to sides, 1,1

A_Created by Incision, 1, 1

A_Crossed, 1, 1

A_Curve/bow down to torso, 1, 1

A_Down at Sides, 1, 1

A_Downward Pointed Stumps, 1, 1

A_Folded, 1, 1

A_Freely Modeled, 1, 1

A_Holes at end, 1, 1

A_Horizontal Stumps, 1, 1

A_Incised decoration on arms, 1, 1

A_Indentation on Arms, 1, 1

A_Indentation on back of elbows, 1, 1

A_Intentionally absent arms, 1, 1

A_Meet at Center of Torso, 1, 1

A_On abdomen, 1, 1

A_On chest below breast, 1, 1

A_Pierced through upper arm, 1, 1

A_Raised straight Above Head, 1, 1
A_In back and front center, 1, 1

\section{Bottom}

AP_Incised, 1, 1

AP_Indented, 1, 1

Bu_Hollow, 1, 1

Bu_Horizontal Hole in hip, 1, 1

Bu_Horizontal Line Below, 1, 1

Bu_Incised Circles, 1, 1

Bu_Indents, 1, 1

Bu_Modeled Buttocks, 1, 1

Bu_Moderate Protrusion, 1, 1

Bu_Vertical Line as Division, 1 ,

D_1 incision for toes, 1, 1

D_3 incisions for toes, 1, 1

D_4 incisions for toes, 1, 1

D_5 incisions for toes, 1, 1

D_Modeled toes, 1, 1

Ft_Flat disc-shaped, 1, 1

Ft_Incised decoration or footware, 1, 1

Ft_Roughly foot-shaped, 1, 1

G_Circular Pubic Area, 1, 1

G_Hole Under Rearend Text, 1, 1

G_Incised pubic area trapezoidal or square, 1,1

G_Incised Pubic Triangle, 1, 1

G_Indented Pubic Area , 1, 1

G_Modeled female pubic area,

1,1

G_Modeled Penis

G_Pubic Area, 1, 1 
Top

Ey_Pierced through, 1, 1

Ey_Pupils, 1, 1

Ey_Rounded Eyelids, 1, 1

Ey_Semi-circular Eyes, 1, 1

Ey_Socket Area impressed, 1, 1

Ey_Straight Eyelids, 1, 1

F_Comes to point at Nose, 1, 1

F_Flat Face, 1, 1

F_Intentionally Absent Face, 1, 1

F_Modeled in Round, 1, 1

H_Almost flat vertically, 1, 1

H_Circular, 1, 1

H_Concave Head, 1, 1

H_Conical or Slightly Pointy, 1, 1

H_Cylindrical, 1, 1

H_Flat Headdress, 1, 1

H_Flat in Back, 1, 1

H_Floppy Headdress, 1, 1

H_Hat, hair bun or pigtail, 1, 1

H_Hole in Top of Head, 1, 1

H_Hole Vertical Through, 1, 1

H_Hollow, 1, 1

H_Incisions to Indicate Hair or

Headdress, 1, 1

H_Inclined Back, 1, 1

H_Intentionally Absent, 1, 1

H_Modeled Forehead, 1, 1

H_Pinched stump, 1, 1

H_Rectangular, 1, 1
Middle

A_Reach forward, 1, 1

A_Relief Modeled, 1, 1

A_Rounded Stumps, 1, 1

A_To the side of abdomen, 1, 1

A_Upward Pointed Stumps, 1, 1

B_Bump on Back, 1, 1

B_Cavity/Hood, 1, 1

B_Flat, 1, 1

B_Incised Spine, 1, 1

B_Incision across top, 1, 1

B_Incision on Back, 1, 1

B_Indentations, 1, 1

B_Indentations across top, 1, 1

B_Modeled Spine, 1, 1

B_Ribs, 1,1

B_Rounded, 1, 1

B_Spine Indicated, 1, 1

B_X On back, 1, 1

BC_Applique Breasts, 1, 1

BC_Asymmetrical, 1, 1

BC_Bolero Vest, 1, 1

BC_Incised Decoration Across Top of Chest, 1,1

BC_Indented Breasts, 1, 1

BC_Indented Decoration Across Top of Chest, 1, 1

BC_Indented Nipple, 1, 1

BC_Intentionally Absent Breasts, 1, 1

BC_Modeled Breasts, 1, 1

BC_Pendulous Breasts, 1, 1

\section{Bottom}

G_Vagina Incised, 1, 1

G_Vagina Indent, 1, 1

L_Ankle Area Protrusion, 1, 1

L_Applique knees, 1, 1

L_Bent at hip, 1, 1

L_Bent at knee, 1, 1

L_Circular base, 1, 1

L_Concave Base, 1, 1

L_Conical Base, 1, 1

L_Cubical base, 1, 1

L_Cylindrical Base, 1, 1

L_End in a Point, 1, 1

L_Formed Separately, 1, 1

L_Hole vertical through center of leg, 1, 1

L_Incised decoration, 1, 1

L_Incision above knee, 1, 1

L_Indented decoration, 1, 1

L_Indicated with incision, 1, 1

L_Indicated with modeling, 1 ,

1

L_Intentionally Absent Legs, 1, 1

L_Knee indicated with incision, 1,1

L_Modeled knee, 1, 1

L_Modeled Shin, 1, 1

L_Ovoid Base, 1, 1

L_Semicircular base no legs, 1, 1

L_Separated, 1, 1

L_Square Base, 1, 1

L_T-shaped Base, 1, 1 
(cont.)

\section{Top}

Middle

\section{Bottom}

$\begin{array}{lll}\text { H_Roughly Spherical, 1, 1 } & \text { BC_Round Breasts, 1, 1 } & \text { P_Seated } \\ \begin{array}{l}\text { H_Rounded Headdress or Back of } \\ \quad \text { Bead, } 1,1\end{array} & \text { BC_Triangular Breasts, 1, 1 } & \\ \begin{array}{l}\text { H_Stump With Rounded Point, } \\ \quad \text { 1, 1 }\end{array} & \text { BC_Unlevel Breasts, 1, 1 } & \text { P_Leaning backward } \\ \text { H_Triangular, 1, } 1 & \text { BC_X Crossing torso, 1, 1 } & \text { P_Leaning forward }\end{array}$

H_Upsidedown Conical Head, 1, 1 D_2 incsions for fingers, 1, 1

M_Circular incised Mouth, 1, 1 D_3 incisions for fingers, 1, 1

M_Dashes below, 1, 1 D_4 incisions for fingers, 1, 1

M_Indentations below, 1, $1 \quad$ D_5 incisions for fingers, 1, 1

M_Intentionally Absent Mouth D_Incised wedge-shaped fingers, 1, 1

Text, 1,1

M_Line of Indentations to $\quad$ D_Modeled Fingers, 1, 1

indicate, 1,1

M_Modeled Mouth, 1, $1 \quad$ HA_Both on Breasts, 1, 1

M_Semi-circular Mouth, 1, 1 HA_Intentionally absent hands, 1, 1

M_Single Indentation, 1, 1 HA_Made Through Incision, 1, 1

M_Slit, 1, 1 HA_Neither on Breast, 1, 1

N_Horizontal hole in nose, 1, $1 \quad$ HA_On Belly, 1, 1

N_Incised, 1, $1 \quad$ HA_One b/t Breasts, 1, 1

N_Indented Nostril Hole(s) , 1, 1 HA_One on Breast, 1, 1

N_Intentionally Absent Nose, 1, 1 Nv_Fingernail Navel, 1, 1

N_Modeled Beak, 1, $1 \quad$ Nv_Horizontal hole through belly, 1, 1

N_Modeled from top of head, 1, 1 Nv_Incised navel, 1, 1

N_Modeled Non-beak, 1, $1 \quad$ Nv_Indented navel, 1, 1

N_Pierced Nostril Hole, 1, $1 \quad$ Nv_Protruding circle around navel, 1 ,

N_Pinched, $1,1 \quad$ Nv_Protruding navel, 1,1

Nk_Appliqué Decoration, 1, $1 \quad$ Nv_Vertical hole through belly, 1, 1

Nk_Dot Decoration, 1, 1 Sh_Indented Decoration, 1, 1

Nk_Elongated, 1, $1 \quad$ Sh_Sloping, 1, 1

NK_Horizontal hole through, 1, 1 Sh_Square, 1, 1

Nk_Incised Decoration, 1, 1 Sh_Straight, 1, 1

Nk_Inward Curve Indication, 1, 1 T_Appliqué Decoration, 1, 1

Nk_Non_centrally placed, 1, $1 \quad$ T_Belly, 1, 1 


\begin{tabular}{|c|c|}
\hline Top & Bottom \\
\hline Nk_Round Modeled, 1,1 & $\begin{array}{l}\text { T_Cavity in Area, } 1,1 \\
\text { T_Conical, } 1,1 \\
\text { T_Cylindrical Torso, } 1,1 \\
\text { T_Diagonal incised band with dots, } 1 \text {, } \\
1 \\
\text { T_Hole Through Center of Bottom, 1, } 1 \\
\text { T_Hole Through Center of Top, 1, 1 } \\
\text { T_Incision or indentation middle of } \\
\text { chest, } 1,1 \\
\text { T_One side bias, } 1,1 \\
\text { T_Other incised decoration, 1, } 1 \\
\text { T_Roughly rectangular, } 1,1 \\
\text { T_With curves, } 1,1 \\
\text { W_Incision at Waist Distinct from } \\
\text { Pubic Area, 1, } 1 \\
\text { W_Love Handles, } 1,1 \\
\text { W_Modeled Waist, } 1,1\end{array}$ \\
\hline
\end{tabular}

\section{Appendix 4.3. List of Ceramic Attributes}

\begin{tabular}{ll}
\hline Ceramic Attributes & Weights \\
\hline Height & 2 \\
Diameter & 2 \\
Handle & 1 \\
HeightDiameterRatio & 2 \\
WidthCenterBody & 2 \\
Vertical Rim & 2 \\
Inverted Rim & 2 \\
Everted Rim & 2 \\
Angled Rim & 2 \\
S-Shaped Profile & 2 \\
Semicircular Handle & 1 \\
Spout & 2 \\
\hline
\end{tabular}




\section{References}

Adams, William Y., and Ernest W. Adams. 1991. Archaeological Typology and Practical Reality: A Dialectical Approach to Artifact Classification and Sorting. Cambridge: Cambridge University Press.

Aldenderfer, Mark. 1982. "Methods of Cluster Validation for Archaeology." World Archaeology 14 (1): 61-72.

Alkım, U. Bahadir, Handan Alkım, and Önder Bilgi. 1988. Íkiztepe I, Birincive İkinciDönem Kazıları. Ankara: Turk Tarih Kurumu Basimevi.

Aydıngün, Şengül, and H. Ali Ekinci. 1999. "Burdur Müzesinde Korunan Çaykenar Tip İdollerin Öncüsü Pişmiş Toprak Bir İdol.” Arkeolojive Sanat 9o: 29-31.

Bartel, Brad. 1981. "Cultural Associations and Mechanisms of Change in Anthropomorphic Figurines during the Neolithic in the Eastern Mediterranean Basin." WorldArchaeology $13(1): 73-86$.

Biehl, Peter F. 1996. "Symbolic Communication Systems: Symbols on Anthropomorphic Figurines of the Neolithic and Chalcolithic from South-Eastern Europe." JEurArch 4: $153-176$.

Bilgi, Önder. 2001. Metallurgists of the Central Black Sea Region: Protohistoric Age; A New Perspective on the Question of the Indo-Europeans' Original Homeland. Istanbul: TASK.

Brugger, Peter. 1999. "One Hundred Years of an Ambiguous Figure: Happy Birthday, Duck/Rabbit!" Perceptual \& Motor Skill 89: 973-977.

Brugger, Peter, and Susanne Brugger. 1993. "The Easter Bunny in October: Is It Disguised as a Duck?" Perceptual \& Motor Skills 76: 577-578.

Buccellati, Giorgio. 2007. "Non-linear Archaeology." Backdirt: Annual Review of the Cotsen Institute of Archaeology, 37-39.

Carroll, Lewis, and John Tenniel. 1896. Alice's Adventures in Wonderland. New York: Hurst.

Feldman, Marian H. 2014. Communities of Style: Portable Luxury Arts, Identity, and Collective Memory in the Iron Age Levant. Chicago: University of Chicago Press.

Fliegende Blätter. 1892. <https://doi.org/10.11588/diglit.2137\#0147>.

Ford, James A. 1954. "Spaulding's Review of Ford." AmA 56 (1): 109-112.

Ford, James A., and Julian H. Steward. 1954. "On the Concept of Types." AmA 56 (1): 42-57.

Gansell, Amy R., Jan-Willem van de Meent, Sakellarios Zairis, and Chris H. Wiggins. 2014. "Stylistic Clusters and the Syrian/South Syrian Tradition of First Millennium вCE Levantine Ivory Carving: A Machine Learning Approach." Journal of Archaeological Science 44: 194-205.

Gnecco, Cristóbal, and Carl Langebaek, eds. 2014. Against Typological Tyranny in Archaeology. New York: Springer.

Gordon, Allan D. 1999. Classification. Boca Raton, FL: Chapman and Hall. 
Guralnick, Eleanor. 1973. "Kouroi, Canon and Men: A Computer Study of Proportions." Computer Studies in the Humanities and Verbal Behavior 4: 77-80.

Hansen, Svend. 2007. Bilder vom Menschen der Steinzeit: Untersuchungen zur anthropomorphen Plastik der Jungsteinzeit und Kupferzeit in Südosteuropa. Mainz: Philipp von Zabern.

Hermon, Sorin, and Franco Niccolucci. 2002. "Estimating Subjectivity of Typologists and Typological Classification with Fuzzy Logic." Acalc 13: 217-232.

Hodder, Ian. 2012. Entangled: An Archaeology of the Relationships between Human and Things. Malden, MA: Wiley-Blackwell.

Korfmann, Manfred. 1983. Demircihüyük: Die Ergebnisse der Ausgrabungen 1975-1978. Vol. 1. Architektur, Stratigraphie und Befunde. Mainz: Philipp von Zabern.

Korfmann, Manfred, and Bernd Kromer. 1993. "Demircihöyük, Beşik-Tepe, Troia- eine Zwischenbilanz zur Chronologie dreier Orte in Westanatolien." StTr 3: 135-171.

Kökten, Kiliç, Nimet Özgüç, and Tahsin Özgüç. 1945. "1940 ve 1941 Yılında Tarih Kurumu Adına Yapılan Samsun Bölgesi Hakkında İlk Kısa Rapor." Belleten 9 (35): 361-40o.

Madsen, Torsten. 2007. "Multivariate Data Analysis with PCA, CA AND MS." Introduction to CAPCA Programme. <http://www.archaeoinfo.dk/>.

Makowski, Maciej. 2005. "Anthropomorphic Figurines of Early Bronze Age Anatolia." Archeologia 56: 7-30.

Martino, Shannon. 2012. "The Intersection of Culture and Agency as Seen Through the Shared Figurine Genre of the Prehistoric Southwest Black Sea." PhD diss., University of Philadelphia.

Obladen-Kauder, Julia. 1996. “Die Klienfunde aus Ton, Knochen und Metall.” In Demircihüyük: Die Ergebnisse der Ausgrabungen 1975-8. Vol. 4. Die Klienfunde, edited by Manfred Korfmann, 209-314. Mainz: Philipp von Zabern.

Renfrew, Colin. 1969. "The Development and Chronology of the Early Cycladic Figurines." AJA 73: 1-32.

Roy, Ellen, and David Reason. 1979. Classifications in their Social Context. London: Academic Press.

Seeher, Jürgen. 1988. Demircihüyük: Die Ergebnisse der Ausgrabungen 1975-1978 3,2 3,2: Die Kerami; 2, C, Die frühbronzezeitliche Keramik der jüngeren Phasen (ab Phase H). Mainz am Rhein: Philipp von Zabern.

Seeher, Jürgen. 1992. “Die Nekropole von Demircihüyük-Sarkket.” IM. 42: 5-19.

Spaulding, Albert C. 1953. "Review: Measurements of Some Prehistoric Design Developments in the Southeastern States by James A. Ford." AmA 55 (4): $5^{88-591 .}$

Spaulding, Albert C. 1954. "Spaulding's Review of Ford." AmA 56 (1): 109-114.

Thissen, Laurens. 1993. "New Insights in Balkan-Anatolian Connections in the Late Chalcolithic: Old Evidence from the Turkish Black Sea Littoral." AnatS 43: 207-237.

Tixier, Jacques. 1967. "Procédés d'Analyse et Questions de Terminologie dans l'Etude des Ensembles Industriels du Paléolithique Récent et de l'Epipaléolithique en Afrique 
du Nord-Ouest." In Background to Evolution in Africa, edited by Walter W. Bishop and J. Desmond Clark. Chicago: University of Chicago Press, 771-820.

Ucko, Peter. 1968. Anthropomorphic Figurines of Predynastic Egypt and Neolithic Crete, with Comparative Material from the Prehistoric Near East and Mainland Greece. London: Andrew Szmidla.

Weinberg, Saul S. 1951. "Neolithic Figurines and Aegean Interrelations." AJA 55 (2): 121-133. 


\section{PART 3}

Texts 